\title{
Setting the Bar High or Setting Up to Fail? Interpretations and Implications of The EXPLORE Study (HPTN 015)
}

\author{
Seth C. Kalichman • Larissa Zohren • \\ Lisa A. Eaton
}

Published online: 30 August 2013

(c) Springer Science+Business Media New York 2013

\begin{abstract}
Controlled studies show that HIV risk reduction counseling significantly increases condom use, reduces unprotected sex and prevents sexually transmitted infections. Nevertheless, without evidence of reducing HIV incidence, these interventions are generally discarded. One trial, the EXPLORE study, was designed to test whether ten sessions of risk reduction counseling could impact HIV incidence among men who have sex with men in six US cities. Based on epidemiologic models to define effective HIV vaccines, a $35 \%$ reduction in HIV incidence was set a priori as the benchmark of success in this behavioral intervention trial. Results demonstrated a significant effect of the intervention, with more than a $35 \%$ reduction in HIV incidence observed during the initial 12-18 months following counseling. Over an unprecedented 48-month follow-up, however, the effect of counseling on HIV incidence declined to $18 \%$. The current review examined how the scientific literature has thus far judged the outcomes of the EXPLORE study as well as the policy implications of these judgments. We identified 127 articles that cited the EXPLORE study since its publication. Among articles that discuss the HIV incidence outcomes, $20 \%$ judged the intervention effective and $80 \%$ judged the intervention ineffective. The overwhelmingly negative interpretation of the EXPLORE study outcomes is reflected in public policies and prevention planning. We conclude that using a vaccine standard to define success led to a
\end{abstract}

S. C. Kalichman $(\bowtie) \cdot$ L. Zohren

Department of Psychology, University of Connecticut, 406 Babbidge Road, Storrs, CT 06269, USA

e-mail: seth.k@uconn.edu

L. A. Eaton

Department of Human Development and Family Studies, University of Connecticut, Storrs, CT 06269, USA broad discrediting of the benefits of behavioral counseling and, ultimately, adversely impacted policies critical to the field of HIV prevention.

Keywords HIV prevention - EXPLORE - HIV incidence $\cdot$ Men who have sex with men

\section{Introduction}

The ultimate goal of any approach to HIV prevention is a meaningful reduction in new HIV infections. There are, unfortunately, few prevention interventions that have examined HIV infections as their endpoint and very few have achieved the goal of reducing HIV incidence. However, once demonstrated to reduce HIV incidence, interventions have had an impact on public health policy [1-3]. In order to use HIV incidence as their endpoint, clinical trials must be large in size, expansive in scope, and expensive in cost. For these reasons, HIV prevention trials typically rely on proxy outcomes, such as non-HIV incident sexually transmitted infections (STI), and behaviors that mediate (i.e., unprotected sex and injection equipment sharing) or mitigate (i.e., condom use and injection equipment cleaning) HIV transmission [4, 5]. Findings from numerous carefully controlled randomized clinical trials are remarkably positive and consistent; behavioral interventions that are guided by principles of behavior change effectively increase protective practices across nearly every population of importance in HIV prevention [6-8]. Unfortunately, because these intervention outcomes focus on behavior change, the results have been met with skepticism and often dismissed with claims that self-report is invalid and behavior change does not necessarily lead to disease prevention [9-11]. 
The next generation of HIV prevention trials answered the limitations of self-reported behavior change by increasing the size and scope of studies to include incident STI as their endpoint. This shift in direction allowed for reasonable approximations of HIV prevention without the expense of conducting trials powered for detecting reductions in incident HIV infections. The inference that an incident STI approximates HIV transmission risk is based on the fact that HIV is itself an STI. In addition, there is high-prevalence of other STI in populations at greatest risk for HIV infection and STI play a pivotal role in HIV susceptibility and infectiousness [12, 13]. Findings from prevention trials that have included incident STI as their endpoint mirror those trials that report only behavioral outcomes [14, 15]. Nevertheless, skeptics of behavioral interventions for HIV prevention remain unsatisfied, claiming that the biological bases and transmission dynamics of incident STI are too different from HIV to permit inferences regarding HIV prevention. Thus, once again the goal posts were pushed back; the only convincing evidence of HIV prevention efficacy would be reducing HIV incidence [16].

In the current paper, we examined the outcomes of the EXPLORE study-the only behavioral intervention trial aimed to detect differences in sexually transmitted HIV incidence. We set out to review how the outcomes of the EXPLORE study have been judged in the years following its completion. We begin with an overview of the design of the trial and rationale for evaluating its effectiveness. We then provide a review of the published research that has cited the EXPLORE study outcome paper [17] to determine how the HIV incidence outcomes have been judged. Finally, we discuss how interpretations of the EXPLORE study have influenced HIV prevention policy.

\section{The EXPLORE Study (HPTN 015)}

Designed as the definitive test of behavior change interventions to reduce HIV incidence, the EXPLORE study [17] enrolled 4,295 men who have sex with men between 1999 and 2003 in six US cities-Boston, Chicago, Denver, New York, San Francisco, and Seattle. The counseling in this trial was based on principles of motivational interviewing and social-cognitive behavioral skills building models for health behavior change [18]. Preliminary studies identified key behavioral targets aimed directly at reducing HIV risks. For example, as a result of initial developmental studies, sexual pleasure was considered the basis for engaging in unprotected anal sex and was incorporated into the counseling. Substance use was also a prominent feature of risk and became a major focus in counseling. Men randomized to the EXPLORE study experimental counseling received ten prevention counseling modules in just as many sessions over 4-6 months. Each session lasted an average of just under $40 \mathrm{~min}$. Nearly $75 \%$ of EXPLORE participants had received all of the counseling sessions, with an additional $12 \%$ receiving between six and nine sessions. EXPLORE also provided maintenance counseling every 3 months, as well as HIV testing every 6 months for the duration of the study. Men in the comparison intervention received HIV testing every 6 months accompanied by ongoing risk reduction counseling that has itself been demonstrated highly-effective for reducing incident STI in long-term follow-up [19].

\section{Rationale for Defining Success}

The EXPLORE study defined effectiveness a priori as reducing HIV incidence by $35 \%$. The decision rules described in the trial executive summary state:

To be specific, the EXPLORE study was designed so that the intervention strategy would be declared beneficial if the reduction in HIV incidence was statistically significantly above $10 \%$ (that is, that the lower bound of the confidence interval was above $10 \%$ ). If not, and the reduction in HIV incidence was statistically significantly below $35 \%$ (that is, the upper bound of the confidence interval was below $35 \%$ ), the benefit of the intervention strategy would be ruled out. In case neither was true, the intervention would be considered plausibly efficacious with merit for further evaluation, possibly with select refinements. With the target sample size of 4,350 and an expected HIV incidence of 1.55 per 100 person years in the standard arm, if the true reduction in HIV incidence was $35 \%$, there would be $3.0 \%$ chance of ruling out benefit, $50.0 \%$ chance of declaring benefit, and $46.9 \%$ chance of stating plausibly efficacious. Furthermore, if the true reduction in HIV incidence was $0 \%$, there would be an $75.0 \%$ chance of ruling out benefit. [(EXPLORE Executive Summary [20], p. 3)].

Defining HIV prevention success as $35 \%$ reduction in HIV incidence appears rooted in epidemiological models used to estimate vaccine efficacy. The benchmark of $35 \%$ reduction in HIV incidence may therefore be practical for 'permanently' protective interventions, such as vaccines and male circumcision. However, it is unreasonable to expect that the effects of any behavioral intervention would hold for the duration of one's lifetime. Is expecting a $35 \%$ reduction in HIV incidence over 48 months a legitimate standard to apply to behavioral interventions? Furthermore, given that permanently protective interventions are rare (there is no 
effective HIV vaccine), limited by risk group (data suggest limited benefits of male circumcision for MSM) and partially protective (male circumcision is $50 \%$ effective), is it reasonable to declare behavioral interventions that are effective over 18 months but not 48 months as unsuccessful? [8, 21].

Over 48 months of follow-up, the HIV incidence for men who received the EXPLORE counseling was 1.9 infections per 100 person years, compared to 2.3 per 100 person years for men who received semi-annual testing and counseling, an $18 \%$ difference in HIV incidence. Thus, over the course of 4 years (average follow-up 3.25 years), the difference between the conditions was not deemed significant. However, the 12-month follow-up outcomes exceeded the $35 \%$ bar set for reducing in HIV incidence, demonstrating a difference between conditions of $39 \%$ [22]. The impact of the EXPLORE counseling has therefore been judged against two standards. As a behavioral intervention, a $39 \%$ reduction in HIV incidence over 12-18 months is an irrefutable success. As discussed by Coates et al. [22]. "Had the study terminated when behavioural studies are usually stopped (i.e., at 12 months' follow-up), the intervention would have been declared effective." (p. 672) In contrast, when held to a standard set for HIV vaccines, an $18 \%$ reduction in HIV incidence over 48 months is considered a failure. The policy implications of these two disparate conclusions have the potential to determine the direction of HIV prevention research, policy, and practice. We therefore examined how the field has thus far judged the outcomes of the EXPLORE study.

\section{Method of Review}

We conducted a systematic search using Thomson Reuters Web of Knowledge (version 1.0) and Google Scholar to identify all published articles that have cited the EXPLORE study outcome paper by Koblin et al. [17]. Our initial search was conducted in October 2012 and we performed a final search in March 2013. We retrieved the full text for all published papers and searched the articles for the EXPLORE study citation. We extracted the verbatim text where the EXPLORE study was cited in the original content. We then coded the extracted text blind to author, title, and journal.

Articles were first sorted into two groups. The first group was defined as non-judging, that is the EXPLORE study was cited but not judged as to its effectiveness for preventing HIV infections. These articles cited EXPLORE for use in secondary analyses, use of measurement instruments, with reference to the type of counseling, or with respect to the non-HIV outcomes without drawing conclusions on the impact of the intervention on HIV incidence. For example, one article that cited the EXPLORE study stated "Reviews showed that intervention programs for MSM are effective in reducing risk behaviors among HIV risk groups" [23], without drawing conclusions on the HIV incidence endpoint. In addition, articles that discussed the rates of behavior and disease in the trial without reference to the intervention effects were considered non-judging; for example, "In the EXPLORE cohort study, a significant increase in the risk of HIV infection was associated with recently acquired and prevalent HSV-2 infection-by 3.6-fold and 1.5-fold, respectively" [24]. Finally, articles that made broad statements about intervention outcomes without specifically discussing EXPLORE were coded as non-judging; for example, "Behavioral interventions, contingency management programs and referral to outpatient treatment programs have shown promise in decreasing methamphetamine use and reducing risk behaviors associated with the spread of HIV infection." [25].

The balance of articles judged the impact of EXPLORE counseling on HIV incidence. These articles were subjected to a second stage of coding to determine how the outcomes were judged: (a) favorable HIV outcomes (i.e., demonstrated significant reduction in HIV incidence), (b) unfavorable outcomes (i.e., failing to significantly reduce HIV incidence). Two independent coders (the first two authors) examined the extracted text and reached $92 \%$ agreement. Discrepancies were settled by discussion.

\section{Interpretation of the EXPLORE Study in Peer- Reviewed Literature}

Results showed that the EXPLORE study outcome paper was referenced soon after publication, with 53 articles citing the outcomes in the first four years after publication, 19 in the fifth year, and 23 articles citing the outcomes in the sixth year. In total we identified 127 articles citing the EXPLORE outcome paper. For the sake of comparison, we conducted a similar citation search for the primary outcome study from Project RESPECT, which demonstrated reductions from counseling in non-HIV STI that was widely heralded as successful and formed the basis for the control condition in the EXPLORE study. Results showed that in the first 8 years after Project RESPECT was published it had been cited 299 times, more than twice as often as the EXPLORE study, a statistically significant difference, $t(14)=4.04, p<0.001$ (see Fig. 1).

Content coding of the articles that cited EXPLORE showed that $92(72 \%)$ of the 127 articles citing the study did not judge the HIV incidence outcomes. A total of 34 articles drew conclusions regarding the effects of EXPLORE counseling on HIV incidence. Table 1 shows 


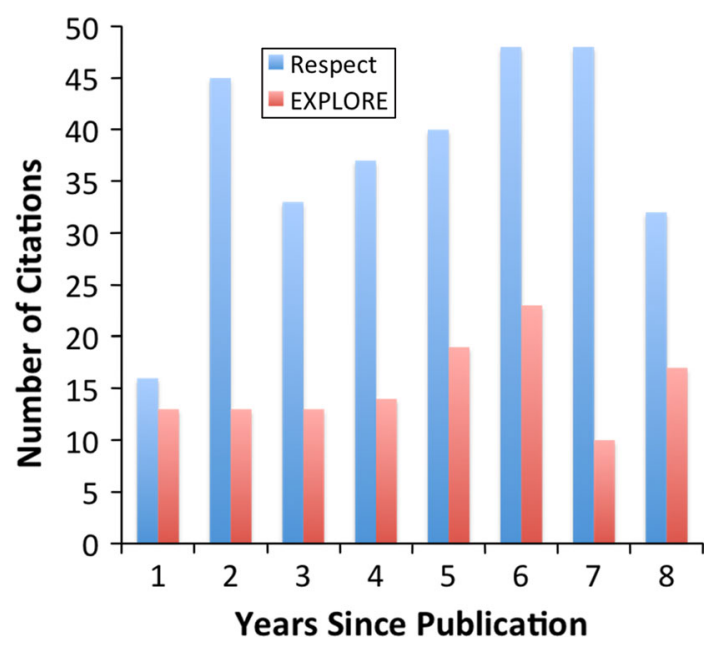

Fig. 1 Number of articles citing project respect (1999-2006) and the EXPLORE study (2005-2012)

the positive and Table 2 shows the negative coded judgments of the EXPLORE study HIV incidence outcomes. Results showed that 27 of the articles (80\%) judged EXPLORE as ineffective at reducing HIV incidence and 7 (20\%) judged EXPLORE as effectively reducing HIV incidence. Examining the content of Table 2 shows that even the most positive interpretations of the EXPLORE study outcomes take into account the 48-month follow-up and do not suggest overwhelming success. Thus, across all citations of the EXPLORE outcome paper, only $5 \%$ judged the trial effective in reducing HIV incidence compared to $21 \%$ that judged the outcomes ineffective.

\section{Interpretations of the EXPLORE Study in Public Policy}

Whether or not EXPLORE counseling should be held to the same standard as an HIV vaccine may be worthy of academic debate. Nevertheless concluding that EXPLORE was not effective in reducing HIV incidence has had a significant real world impact on public health policy. At worst, the 48-month outcomes from the EXPLORE study have provided long-time skeptics of behavioral interventions with a definitive confirmation for their beliefs that risk reduction counseling is ineffective. For example, in their 2006 HIV Testing Guidelines, the CDC refers to EXPLORE as offering limited evidence of efficacy for risk reduction counseling. Specifically, as part of their basis for removing the requirement to conduct risk reduction counseling in conjunction with HIV testing, the CDC stated the following about EXPLORE;

The benefit of providing prevention counseling in conjunction with HIV testing is less clear. HIV counseling with testing has been demonstrated to be an effective intervention for HIV-infected participants, who increased their safer behaviors and decreased their risk behaviors; HIV counseling and testing as implemented in the studies had little effect on HIVnegative participants. However, randomized controlled trials have demonstrated that the nature and duration of prevention counseling might influence its effectiveness. (referenced the EXPLORE study) Carefully controlled, theory-based prevention counseling in STD clinics has helped HIV-negative participants reduce their risk behaviors compared with participants who received only a didactic prevention message from health-care providers. A more intensive intervention among HIV-negative MSM at high risk, consisting of ten theory-based individual counseling sessions followed by maintenance sessions every 3 months, resulted in reductions in unprotected sex with partners who were HIV-infected or of unknown status, compared with MSM who received structured prevention counseling only twice yearly. (references the EXPLORE study). [[26] p. 15].

The implication is that risk reduction counseling may change behavior and may even reduce the risks for STI, but not HIV.

The CDC has also identified EXPLORE counseling as an 'effective intervention' for distribution in its Diffusion of Effective Behavioral Interventions (DEBI) program. (see http://www.cdc.gov/hiv/topics/research/prs/resources/ factsheets/EXPLORE.htm) In describing the "Key Intervention Effects", the CDC notes that EXPLORE decreased risk behavior. They specifically state, "Men in the intervention group were significantly less likely to report any unprotected anal sex, serodiscordant unprotected anal sex, and serodiscordant receptive unprotected anal sex at the 12 and 18-month follow-ups as compared to men receiving the standard comparison intervention ( $p$ 's $<0.001)$." However, under a separate heading, "Considerations", The CDC states, "A modest $18 \%$ reduction in HIV incidence, the primary outcome, was observed in the intervention relative to control arm; however, this did not achieve statistical significance."

The US National HIV Prevention Strategy, arguably the single most important policy statement guiding US HIV prevention efforts, only cites the EXPLORE study once. Consistent with the bulk of the research literature and the conclusions of the CDC, the National Strategy cites EXPLORE by stating the following, "Even though these [risk reduction] interventions have not been proven to reduce HIV infections, they promote responsible sexual behaviors that may lower a person's risk for becoming infected with HIV and some have been associated with reducing STIs" [[27], p. 17] Given the importance of the 
Table 1 Negative interpretations of the EXPLORE study HIV incidence outcomes in published articles

\begin{tabular}{|c|c|c|}
\hline First author/reference & Years & Unfavorable interpretation \\
\hline Auerbach et al. [33] & 2006 & $\begin{array}{l}\text { A large multisite behavioural intervention trial in the United States among men who } \\
\text { have sex with men, and which included HIV incidence as an outcome measure, found } \\
\text { an } 18.2 \% \text { lower rate of HIV infection (15.7 \% after adjustment for baseline } \\
\text { covariates) in the intervention group compared with the control group and a } 20.5 \% \\
\text { lower incidence of unprotected receptive anal intercourse with partners who were } \\
\text { HIV-positive or of unknown serostatus in the intervention group compared with the } \\
\text { control group. Although the behavioural outcome was statistically significant, the HIV } \\
\text { incidence outcome was not }\end{array}$ \\
\hline
\end{tabular}

Bedoya et al. [34]

Berg et al. [35]

Brown et al. [36]

Golden et al. [37]

Grant et al. [3]

Grant et al. [38]

Gross et al. [39]

Herbst et al. [40]
It was previously reported that the EXPLORE intervention did not significantly reduce the risk of HIV infection: a modest $18 \%(95 \% \mathrm{CI}-5,36 \%)$ reduction in risk of HIV infection was observed

We emphasize that although not statistically different, the rate of HIV acquisition in the EXPLORE Study was almost $16 \%$ lower in the first 18 months of follow-up among MSM receiving MI compared with MSM receiving twice yearly counseling on risk reduction. This is a clinically important result

Although there was no significant reduction in HIV incidence (intervention effect 5.7, $95 \%$ confidence interval (CI) $-8.4,34.4$ ), a statistically significant reduction of $20.5 \%$ (95\% CI 10.9, 29.0) in unprotected receptive anal intercourse with an HIVpositive or unknown serostatus partner was detected in the behavioral intervention arm. The intensive, 10-session risk reduction behavioral intervention tested in the EXPLORE study did not reduce HIV incidence to a statistically significant degree

Unfortunately, these data are discouraging, with a large, intense ten-session intervention trial demonstrating no significant impact on HIV incidence

Intensive counseling in behavioral risk reduction for such subjects has not been shown to be better than standard counseling

Even as available and proven prevention interventions are used, the HIV pandemic will not be stopped solely by talking to those at-risk

The most labor- intensive counseling strategy evaluated to date has demonstrated no sustained impact on rates of HIV acquisition.

In one study, incident HIV at the 6-month post-baseline follow-up was in the desired direction but non-significant ( $p$ 0.07); results reported at subsequent follow-ups ranging from 12 to 48 months post-baseline were inconsistent and non-significant

The EXPLORE study, a trial conducted in six US cities, reported a significant reduction in self-reported UAI (OR $0.81,95 \%$ CI $0.71-0.93$ ) and a borderline significant decrease in incident HIV (OR 0.62, $95 \%$ CI 0.36 -1.06) after 12 months of follow-up

Four interventions were identified as having produced a significant reduction in new STDs over a minimum of 12 months after exposure to the intervention. The intervention that measured HIV incidence did not significantly reduce the number of new infections

Randomized trials of HIV risk behavioral interventions-particularly for MSM-have generally used two-group designs: an attention-control group (e.g., content materials unrelated to intervention content) or a standard group (e.g., HIV counseling and testing), but rarely both. These interventions generally found no difference between the two groups in HIV risk outcomes

Among participants reporting CSA (child sexual abuse), the EXPLORE intervention had no effect in reducing HIV infection rates. Participants reporting CSA were significantly more likely to have symptoms of depression and use nonprescription drugs

HIV counseling can be an important HIV prevention strategy, although its efficacy in reducing risk behaviors is still being evaluated (CDC 2001). Koblin et al. [17] show that no long-term change is possible

For example, the most recent large-scale HIV prevention behavioral intervention among MSM failed to find a significant effect in reducing HIV risk behaviors.

Prior behavioral intervention trials have observed decay of intervention effects over time

All seven behavioral interventions yielded flat results 
Table 1 continued

\begin{tabular}{lll}
\hline First author/reference & Years & Unfavorable interpretation \\
\hline Pilcher et al. [47] & 2010 & $\begin{array}{l}\text { Meanwhile, although numerous studies have found that individual and small group } \\
\text { counseling interventions can reduce self-reported, high-risk sexual behavior, the only } \\
\text { randomized trial, to our knowledge, to evaluate a behavioral intervention with use of }\end{array}$ \\
& $\begin{array}{l}\text { HIV acquisition as an end point found that repeated counseling sessions were not } \\
\text { effective }\end{array}$
\end{tabular}

Ross et al. [48]

Rotheram-Borus et al. [49]

Rotheram-Borus et al. [50]

Safren et al. [31]

Sanchez et al. [51]

Schneider et al. [52]

2009

Scott-Sheldon et al. [14]

2011

Smith et al. [53]

2012

Sullivan et al. [54]

2012

Zenilman et al. [55]

2005
In any event, none of the trials showed a statistically significant impact on HIV, either in terms of a reduction or an increase; in fact, none approached statistical significance with the possible exception of the EXPLORE trial [adjusted odds ratio $=0.82,95 \%$ CI $0.64-1.05]$

There is evidence both supporting Kamb et al. [19] and disputing Koblin et al. [17] the benefit of more extensive counseling for HIV-negative persons. Despite the equivocal evidence on the effectiveness of the type of pretest counseling typically offered HIV seronegative persons, it may be more sensible to target efforts elsewhere, particularly in low-incidence settings and countries

Randomised controlled trials that test biomedical interventions to reduce STIs have had very mixed results, as have behavioural trials

In addition, the rate of HIV acquisition in the experimental arm was $18.2 \%$ lower than that in the control arm, although the difference was not statistically significant (95\% CI -4.7 to $36.0 \%$ )

The EXPLORE trial, a phase IIb efficacy trial of a 10-session behavioral intervention showed no significant reduction of HIV incidence when compared with regular counseling

Cognitive interventions have not been successful in some other at-risk male populations

Outcomes from this approach demonstrate that enhanced behavioral HIV prevention using multiple group sessions significantly reduces rates of serodiscordant unprotected anal intercourse over standard HIV prevention in the shorter term, with no differences between groups observed to long -term evaluations

Project EXPLORE enrolled 4,295 HIV-uninfected MSM from 6 US cities during 1999-2001 into a randomized, controlled behavioral intervention trial in which the active arm did not significantly reduce HIV incidence compared with the control intervention arm

The HIVNET 015 study (colloquially called EXPLORE) one of the few studies of behavioural interventions in MSM for which reduction of the incidence of HIV infection was an endpoint clearly shows the potential and limitations of behavioural approaches

Nevertheless, although not mentioned specifically in the EXPLORE study, the results were clearly disappointing in that the intensive intervention resulted in only a modest effect
US National HIV Prevention Strategy, its conclusion that behavioral interventions have not been proven to reduce HIV infections surely impacts policy decisions, resource allocation, and statewide prevention planning.

\section{Implications}

The question as to whether EXPLORE counseling reduced HIV incidence clearly depends on how success is defined. Held to a vaccine standard, EXPLORE's outcomes over 48 months do indeed fall short. For instance, the most successful HIV vaccine trial has demonstrated $31 \%$ efficacy over 3 years [28]. However, when held to a standard that is fitting for behavioral interventions, 18 months of follow-up far exceeds what would typically be expected for durability of change in behavior. Thus, reducing HIV incidence over $35 \%$ in this time frame is an unquestionable success. The EXPLORE study outcomes also parallel those of behavioral interventions delivered in far fewer sessions, suggesting the potential for even greater public health impacts of risk reduction counseling [15].

There are other features of the EXPLORE study that question using the 48-month follow-up to define success. Only those participants enrolled in the first year of the study, a fairly small number of men to reliably assess HIV incidence, were represented at 48 months. The HIV incidence in the EXPLORE trial did not decline as a result of epidemiologic trends, therefore yielding adequate statistical power for the analysis. In fact, during the years that the 
Table 2 Positive interpretations of the EXPLORE study HIV incidence outcomes in published articles

\begin{tabular}{|c|c|c|}
\hline First author & Years & Favorable interpretation \\
\hline Chen et al. [56] & 2007 & $\begin{array}{l}\text { Researchers found that in a randomised controlled study an intervention consisting of ten } \\
\text { one-on-one counselling sessions followed by maintenance sessions every } 3 \text { months, was } \\
\text { associated with an } 18.2 \% \text { overall difference between the controlled and intervention } \\
\text { groups }\end{array}$ \\
\hline Donnell et al. [57] & 2010 & $\begin{array}{l}\text { An intervention that targets HIV-uninfected individuals is most efficiently studied with an } \\
\text { individually randomized design. These have been used in most HIV prevention trials, } \\
\text { with intervention efficacies ranging from modest decreases }(25-35 \%) \text { to substantial } \\
\text { reductions }(50-60 \%)\end{array}$ \\
\hline Ickovics et al. [58] & 2008 & $\begin{array}{l}\text { The EXPLORE Study Team found that among men who have sex with men randomized to } \\
\text { ten individual HIV counseling sessions with quarterly maintenance, rate of HIV } \\
\text { acquisition was } 18 \% \text { lower in the intervention compared to standard group, with the } \\
\text { effect most favorable } 12-18 \text { months after the initial HIV test }\end{array}$ \\
\hline Mimiaga et al. [59] & 2006 & $\begin{array}{l}\text { While the intervention did not achieve a targeted level of efficacy }(35 \%) \text { in preventing new } \\
\text { HIV infections compared to semi-annual HIV voluntary counseling and testing, the study } \\
\text { results suggest a possible modest benefit of the intervention in reducing new HIV } \\
\text { infections }\end{array}$ \\
\hline Nielsen et al. [60] & 2005 & $\begin{array}{l}\text { Persons who received intense counseling had an } 18.2 \% \text { lower HIV acquisition rate than } \\
\text { those randomly assigned to the standard intervention, although this difference was } \\
\text { sustainable only in the first } 12-18 \text { months of follow-up }\end{array}$ \\
\hline Rotheram-Borus et al. [61] & 2009 & $\begin{array}{l}\text { These results are encouraging, especially in the face of trials that have shown substantial } \\
\text { relapse after initial responsiveness to efforts to prevent the transmission of HIV }\end{array}$ \\
\hline Wang et al. [62] & 2011 & $\begin{array}{l}\text { Koblin et al. [17] found in the multi-city Project EXPLORE that a } 10 \text {-session intervention } \\
\text { based in part on ME principles brought about reductions both in self reports of sexual risk } \\
\text { behavior and in HIV seroconversion }\end{array}$ \\
\hline
\end{tabular}

EXPLORE study was conducted there were no significant reductions in HIV incidence among MSM in major US cities, including cities where the trial was conducted [29]. The epidemiologic context of the EXPLORE study therefore further bolsters confidence in the 18-month reductions in HIV [30].

Concluding that EXPLORE counseling was more effective in reducing HIV incidence than suggested in the original outcome paper requires using the appropriate standard for a behavioral intervention. We are not the first to point out misrepresentations of the EXPLORE outcomes. Others have similarly concluded that the trial outcomes for reducing HIV incidence should be judged against behavioral interventions and that the methodological features of the trial should be taken into account. For example, although Safren et al. [31] draw conclusions that the HIV incidence outcomes were not statistically significant, they described the EXPLORE study as successful on rational grounds after considering the overlapping features of the experimental and comparison conditions as well as the duration of follow-up. In addition, Eaton et al. [32] performed secondary analyses and concluded on statistical grounds that EXPLORE was effective in reducing HIV incidence through direct and indirect effects of the intervention.

As prevention planners and policy makers contemplate the role of risk reduction counseling and other behavioral interventions in a context that sees little hope for an effective HIV vaccine and in a new era of combination approaches to
HIV prevention, the interpretation of the EXPLORE study outcomes will become even more critical. We conclude that when held to an appropriate standard for behavioral interventions, the EXPLORE counseling was indeed highlyeffective in reducing HIV incidence and offers the potential to significantly alter the course of HIV epidemics. Future references to this uniquely important clinical trial should judge the intervention outcomes more fairly.

Acknowledgments This article was supported by the National Institute of Drug Abuse R01-DA033067 and National Institute of Mental Health R01-MH094230.

\section{References}

1. Bailey RC, Moses S, Parker CB, Agot K, Maclean I, Krieger JN, et al. Male circumcision for HIV prevention in young men in Kisumu, Kenya: a randomised controlled trial. Lancet. 2007;369(9562):643-56.

2. Cohen MS, McCauley M, Gamble TR. HIV treatment as prevention and HPTN 052. Curr Opin HIV AIDS. 2012;7(2):99-105.

3. Grant RM, Lama JR, Anderson PL, McMahan V, Liu AY, Vargas $\mathrm{L}$, et al. Preexposure chemoprophylaxis for HIV prevention in men who have sex with men. N Engl J Med. 2010;363(27):2587-99.

4. Kelly JA, St. Lawrence JS, Hood HV, Brasfield TL. Behavioral intervention to reduce AIDS risk activities. J Consult Clin Psychol. 1989;57:60-7.

5. Valdiserri RO, Lyter DW, Leviton LC, Callahan CM, Kingsley LA, Rinaldo CR. AIDS prevention in homosexual and bisexual men: results of a randomized trial evaluating two risk reduction interventions. AIDS. 1989;3(1):21-6. 
6. Noar SM. Behavioral interventions to reduce HIV-related sexual risk behavior: review and synthesis of meta-analytic evidence. AIDS Behav. 2008;12(3):335-53.

7. Johnson BT, Carey MP, Marsh KL, Levin KD, Scott-Sheldon LA. Interventions to reduce sexual risk for the human immunodeficiency virus in adolescents, 1985-2000: a research synthesis. Arch Pediatr Adolesc Med. 2003;157(4):381-8.

8. Johnson BT, Scott-Sheldon LA, Smoak ND, Lacroix JM, Anderson JR, Carey MP. Behavioral interventions for African Americans to reduce sexual risk of HIV: a meta-analysis of randomized controlled trials. J Acquir Immune Defic Syndr. 2009;51(4):492-501.

9. Fishbein M, Jarvis B. Failure to find a behavioral surrogate for STD incidence-what does it really mean? Sex Transm Dis. 2000;27(8):452-5.

10. Peterman TA, Lin LS, Newman DR, Kamb ML, Bolan G, Zenilman J, et al. Does measured behavior reflect STD risk? An analysis of data from a randomized controlled behavioral intervention study. Project RESPECT Study Group. Sex Transm Dis. 2000;27(8):446-51.

11. Pequegnat W, Fishbein M, Celentano D, Ehrhardt A, Garnett G, Holtgrave D, et al. NIMH/APPC workgroup on behavioral and biological outcomes in HIV/STD prevention studies: a position statement. Sex Transm Dis. 2000;27(3):127-32.

12. Cohen MS. Sexually transmitted diseases enhance HIV transmission: no longer a hypothesis. Lancet. 1998;351(3):5-7.

13. Royce R, Sena A, Cates W, Cohen M. Sexual transmission of HIV. N Engl J Med. 1997;336:1072-8.

14. Scott-Sheldon LA, Huedo-Medina TB, Warren MR, Johnson BT, Carey MP. Efficacy of behavioral interventions to increase condom use and reduce sexually transmitted infections: a meta-analysis, 1991-2010. J Acquir Immune Defic Syndr. 2011;58(5):489-98.

15. Eaton LA, Huedo-Medina TB, Kalichman SC, Pellowski JA, Sagherian MJ, Warren M, et al. Meta-analysis of single-session behavioral interventions to prevent sexually transmitted infections: implications for bundling prevention packages. Am J Public Health. 2012;102(11):e34-44.

16. Padian NS, McCoy SI, Balkus JE, Wasserheit JN. Weighing the gold in the gold standard: challenges in HIV prevention research. AIDS. 2010;24(5):621-35.

17. Koblin B, Chesney M, Coates T. Effects of a behavioural intervention to reduce acquisition of HIV infection among men who have sex with men: the EXPLORE randomised controlled study. Lancet. 2004;364(9428):41-50.

18. Chesney MA, Koblin BA, Barresi PJ, Husnik MJ, Celum CL, Colfax G, et al. An individually tailored intervention for HIV prevention: baseline data from the EXPLORE Study. Am J Public Health. 2003;93(6):933-8.

19. Kamb M, Fishbein M, Douglas J, Rhodes F, Rogers J, Bolan G, et al. Efficacy of risk-reduction counseling to prevent human immunodeficiency virus and sexually transmitted diseases. J Am Med Assoc. 1998;280(13):1161-7.

20. Investigators E. HIVNET 015 executive summary. (Protocol document available from the study team, 2004 in press).

21. Jepson RG, Harris FM, Platt S, Tannahill C. The effectiveness of interventions to change six health behaviours: a review of reviews. BMC public health. 2010;10:538.

22. Coates TJ, Richter L, Caceres C. Behavioural strategies to reduce HIV transmission: how to make them work better. Lancet. 2008;372(9639):669-84.

23. Lau JT, Lau M, Cheung A, Tsui HY. A randomized controlled study to evaluate the efficacy of an Internet-based intervention in reducing HIV risk behaviors among men who have sex with men in Hong Kong. AIDS Care. 2008;20(7):820-8.

24. Lama JR, Lucchetti A, Suarez L, Laguna-Torres VA, Guanira JV, Pun M, et al. Association of herpes simplex virus type 2 infection and syphilis with human immunodeficiency virus infection among men who have sex with men in Peru. J Infect Dis. 2006;194(10):1459-66.

25. Clark T, Marquez C, Hare CB, John MD, Klausner JD. Methamphetamine use, transmission risk behavior and internet use among HIV-infected patients in medical care, San Francisco, 2008. AIDS Behav. 2012;16(2):396-403.

26. Branson BM, Handsfield HH, Lampe MA, Janssen RS, Taylor AW, Lyss SB, et al. Revised recommendations for HIV testing of adults, adolescents, and pregnant women in health-care settings. MMWR Recomm Rep. 2006;55(RR-14):1-17.

27. Policy TWHOoNA. National HIV/AIDS strategy for the United States. Washington DC: US Government; 2010.

28. Rerks-Ngarm S, Pitisuttithum P, Nitayaphan S, Kaewkungwal J, Chiu J, Paris R, et al. Vaccination with ALVAC and AIDSVAX to prevent HIV-1 infection in Thailand. $\mathrm{N}$ Engl $\mathrm{J}$ Med. 2009;361(23):2209-20.

29. Stall R, Duran L, Wisniewski SR, Friedman MS, Marshal MP, McFarland $\mathrm{W}$, et al. Running in place: implications of HIV incidence estimates among urban men who have sex with men in the United States and other industrialized countries. AIDS Behav. 2009;13(4):615-29.

30. Kalichman SC. HIV treatments as prevention (TasP) : primer for behavior-based implementation. New York: Springer; 2013. p. 132.

31. Safren SA, Wingood G, Altice FL. Strategies for primary HIV prevention that target behavioral change. Clin Infect Dis. 2007;45(4):S300-7.

32. Eaton LA, Kalichman SC, Kenny DA, Harel O. A reanalysis of a behavioral intervention to prevent incident HIV infections: Including indirect effects in modeling outcomes of Project EXPLORE. AIDS Care. 2012;25(7):805-11.

33. Auerbach JD, Hayes RJ, Kandathil SM. Overview of effective and promising interventions to prevent HIV infection. World Health Organ Tech Rep Ser. 2006;938:43-78 (discussion 317-41).

34. Bedoya CA, Mimiaga MJ, Beauchamp G, Donnell D, Mayer KH, Safren SA. Predictors of HIV transmission risk behavior and seroconversion among Latino men who have sex with men in Project EXPLORE. AIDS Behav. 2012;16(3):608-17.

35. Berg RC, Ross MW, Tikkanen R. The effectiveness of MI4MSM: how useful is motivational interviewing as an HIV risk prevention program for men who have sex with men? A systematic review. AIDS Educ Prev. 2011;23(6):533-49.

36. Brown EL, Wald A, Hughes JP, Morrow RA, Krantz E, Mayer K, et al. High-risk of human immunodeficiency virus in men who have sex with men with herpes simplex virus type 2 in the EXPLORE study. Am J Epidemiol. 2006;164(8):733-41.

37. Golden MR, Manhart LE. Innovative approaches to the prevention and control of bacterial sexually transmitted infections. Infect Dis Clin North Am. 2005;19(2):513-40.

38. Grant RM, Buchbinder S, Cates W Jr, Clarke E, Coates T, Cohen MS, et al. AIDS. Promote HIV chemoprophylaxis research, don't prevent it. Science. 2005;309(5744):2170-1.

39. Gross M. Bad advice: how not to have sex in an epidemic. Am J Public Health. 2006;96(6):964-6.

40. Herbst JH, Beeker C, Mathew A, McNally T, Passin WF, Kay LS, et al. The effectiveness of individual-, group-, and community-level HIV behavioral risk-reduction interventions for adult men who have sex with men: a systematic review. Am J Prev Med. 2007;32(4 Suppl):S38-67.

41. Lyles CM, Kay LS, Crepaz N, Herbst JH, Passin WF, Kim AS, et al. Best-evidence interventions: findings from a systematic review of HIV behavioral interventions for US populations at high-risk, 2000-2004. Am J Public Health. 2007;97(1):133-43.

42. Mansergh G, Koblin BA, McKirnan DJ, Hudson SM, Flores SA, Wiegand RE, et al. An intervention to reduce HIV risk behavior 
of substance-using men who have sex with men: a two-group randomized trial with a nonrandomized third group. PLoS Med. 2010;7(8):e1000329.

43. Mimiaga MJ, Noonan E, Donnell D, Safren SA, Koenen KC, Gortmaker S, et al. Childhood sexual abuse is highly associated with HIV risk-taking behavior and infection among MSM in the EXPLORE Study. J Acquir Immune Defic Syndr. 2009;51(3):340-8.

44. Miranda AE, Nasser SO, Simon M, Guerra PB. Sant' Anna PM. Risk factors and prevalence of HIV infection in people seeking health care in an STI clinic in Brazil. AIDS Care. 2007;19(1): $75-8$.

45. Morgenstern J, Bux DA Jr, Parsons J, Hagman BT, Wainberg M, Irwin T. Randomized trial to reduce club drug use and HIV risk behaviors among men who have sex with men. J Consult Clin Psychol. 2009;77(4):645-56.

46. Morin SF, Shade SB, Steward WT, Carrico AW, Remien RH, Rotheram-Borus MJ, et al. A behavioral intervention reduces HIV transmission risk by promoting sustained serosorting practices among HIV-infected men who have sex with men. J Acquir Immune Defic Syndr. 2008;49(5):544-51.

47. Pilcher CD, Christopoulos KA, Golden M. Public health rationale for rapid nucleic acid or p24 antigen tests for HIV. J Infect Dis. 2010;201(Suppl 1):S7-15.

48. Ross DA. Behavioural interventions to reduce HIV risk: what works? AIDS. 2010;24(4):S4-14.

49. Rotheram-Borus MJ, Leibowitz AA, Etzel MA. Routine, rapid HIV testing. AIDS Educ Prev. 2006;18(3):273-80.

50. Rotheram-Borus MJ, Wu Z, Li L, Detels R, Liang LJ, Group NCHSPT. Spontaneous remission of sexually transmitted diseases must be considered in randomised controlled trials. Sex Transm Infect. 2011;87(4):305.

51. Sanchez J, Lama JR, Peinado J, Paredes A, Lucchetti A, Russell $\mathrm{K}$, et al. High HIV and ulcerative sexually transmitted infection incidence estimates among men who have sex with men in Peru: awaiting for an effective preventive intervention. J Acquir Immune Defic Syndr. 2009;51(Suppl 1):S47-51.
52. Schneider JA, Dude A, Dinaker M, Kumar V, Laumann EO, Holloway-Beth A, et al. General hygiene, sexual risk behaviour and HIV prevalence in truck drivers from Andhra Pradesh, South India: implications for prevention interventions. Int J STD AIDS. 2009;20(1):39-45.

53. Smith DK, Pals SL, Herbst JH, Shinde S, Carey JW. Development of a clinical screening index predictive of incident HIV infection among men who have sex with men in the United States. J Acquir Immune Defic Syndr. 2012;60(4):421-7.

54. Sullivan PS, Carballo-Diéguez A, Coates T, Goodreau SM, McGowan I, Sanders EJ, et al. Successes and challenges of HIV prevention in men who have sex with men. Lancet. 2012;380(9839):388-99.

55. Zenilman JM. Behavioral interventions-rationale, measurement, and effectiveness. Infect Dis Clin North Am. 2005;19(2):541-62.

56. Chen P. Measures needed to strengthen strategic HIV/AIDS prevention programmes in China. Asia Pac J Public Health. 2007;19(1):3-7.

57. Donnell D, Hughes JP, Fleming TR. Challenges in the design of HIV prevention trials in the United States. J Acquir Immune Defic Syndr. 2010;55(Suppl 2):S136-40.

58. Ickovics JR. "Bundling" HIV prevention: integrating services to promote synergistic gain. Prev Med. 2008;46(3):222-5.

59. Mimiaga MJ, Safren SA, Benet DJ, Manseau MW, DeSousa N, Mayer KH. MSM in HIV prevention trials are sexual partners with each other: An ancillary study to the EXPLORE intervention. AIDS Behav. 2006;10(1):27-34.

60. Metzger DS, Woody G, O'Brien CP. Drug treatment as HIV prevention: a research update. J Acquir Immune Defic Syndr. 2010;55(1):32-6.

61. Rotheram-Borus MJ, Desmond K, Comulada WS, Arnold EM, Johnson M. Healthy Living Trial G. Reducing risky sexual behavior and substance use among currently and formerly homeless adults living with HIV. Am J Public Health. 2009;99(6):1100-7.

62. Wang K, Brown K, Shen SY, Tucker J. Social network-based interventions to promote condom use: a systematic review. AIDS Behav. 2011;15(7):1298-308. 